\title{
EL DIFÍCIL ARTE DE ENSEÑAR LATÍN
}

JUVENAL CRUZ VEGA

Academia de Lenguas Clásicas Fray Alonso de la Veracruz, Puebla

Abel Alemán Mora, Manual de Gramática Latina, Aguascalientes, Universidad Autónoma de Aguascalientes, 2001, $315 \mathrm{pp}$.

La publicación de este nuevo Manual de Gramática Latina puede hacer que las personas que conocen el latín se pregunten con cierto escepticismo: ¿para qué publicar otra gramática latina, habiendo ya tantas?

En español, conozco varias gramáticas de esta lengua. Por ejemplo, la de Blas Goñi, la de Luis Penagos, la de Agustín Mateos, la de José Guillén, la de Rafael Hernández, la de Angelo Altieri; también el método del doctor
Bernabé Navarro Barajas y muchas otras gramáticas que son citadas por el maestro Alemán en la bibliografía de su obra. Por otro lado, el doctor Pedro Tapia Zúñiga, del Instituto de Investigaciones Filológicas de la UNAM, en sus Reflexiones en torno a la metodología del griego clásico, hace una crítica rigurosa que bien se puede aplicar a los manuales tradicionales que pretenden enseñar la lengua latina. Por esta causa es muy difícil y riesgoso proponer un nuevo método para la enseñanza de la lengua de Cicerón. Sin embargo, Abel Alemán, después de haber enseñado y meditado por más de veinte años la lengua latina, ahora nos ha proporcionado su magnífica obra. En su introducción señala que se trata de una 
obra pensada para estudiar con seriedad y cierta profundidad la lengua latina (p. 11).

La obra está estructurada en cinco partes. En la primera (Antecedentes de la lengua latina), el autor ubica la lengua oficial de los romanos como parte de la familia lingüística indoeuropea (p. 15). Asimismo habla de su importancia, sobre todo para las personas que estudian alguna lengua romance. Cuando se refiere a la pronunciación del latín (p.17), sugiere la fonética clásica. Sin embargo no debe olvidarse que existen otras pronunciaciones, por ejemplo la romana, a la cual el autor denomina 'eclesiástica', la francesa, la española y la germana. Pienso que esta última, es la que muchos llaman pronunciación clásica. Quien conoce la lengua griega, sabe que tal pronunciación ha sido elaborada a partir de la pronunciación del griego con la fonética etacista, la cual sistematizaron don Antonio de Nebrija y Erasmo de Rotterdam. Debe reconocerse que todavía se duda cuál sea la verdadera fonética de la lengua latina, pues hay tantas fonéticas cuantas lenguas hay; y cada lengua ha adaptado la fonética del latín a la fonética de su propia lengua.

La segunda parte del texto se refiere a las nociones fundamentales de toda gramática latina (p. 23). El autor presenta una idea general del caso gramatical. A mi modo de ver aquí distingue las dos dimensiones de tal caso, esto es, la función y la forma. Además sugiere varios ejercicios sobre el caso gramatical en español (p. 27), a fin de comprenderlo, primero en nuestra lengua y posteriormente en latín.

En la tercera parte (Morfosintaxis de la lengua latina), Abel Alemán entra propiamente a explorar la morfología y la sintaxis de la lengua de Roma. Pienso que es la porción más completa de su libro. En ésta expone las declinaciones de sustantivos, los adjetivos y pronombres, como también la explicación del verbo sustantivo (p. 47) y la conjugación del verbo transitivo, en donde apunta sus características fundamentales, tales como: la persona, el número, el tiempo, el modo y la voz. Me llama la atención que en el desglose de esta parte de la obra, el autor presente variadas particularidades de la flexión de sustantivos y la conjugación de los verbos, principalmente el uso 
de los deponentes (p. 146).

La sintaxis de la lengua latina es tratada en sus aspectos fundamentales, sobre todo la sintaxis oracional. Aquí aparecen las formas que más se utilizan en los textos latinos, clásicos, medievales y novohispanos, es decir, aparecen oraciones coordinadas y subordinadas ( $p$. 173), oraciones completivas con infinitivo, con subjuntivo y oraciones clasificadas de acuerdo a las conjunciones más usuales. En la cuarta parte de su libro, el maestro Alemán dedica un espacio amplio para asignar las locuciones latinas de uso más frecuente en español; para ser exacto, anota 320 locuciones las cuáles son utilizadas en el léxico jurídico, de lógica, de retórica, de filosofía, de teología, de medicina y hasta en el lenguaje común (pp. 233-244). Algunos ejemplos de lo dicho son: ad hoc, alma mater, in memoriam, vox populi, etc.

En la quinta parte, el autor apunta una porción de textos selectos sobre diálogos latinos, tales como expresiones de saludo (p. 247), de despedida (p. 248), fórmulas para pedir, preguntar, afirmar (p. 251) y otras más. Esta última parte es similar al trabajo que ha elaborado en sus gramáticas latina y griega Blas
Goñi. Asimismo el doctor Tapia Zúñiga en su obra Lecturas Áticas, sólo que éste último lo ha hecho para la enseñanza de la lengua griega.

Considero que también es necesario apuntar que esta obra presenta ciertas exageraciones en cuanto a cumplimiento de propósitos y objetivos. Por ejemplo, eso de traducir frases del latín al español y viceversa, y no lo veo en textos latinos, lo considero lejos de las posibilidades del texto. Incluso los mismos maestros de la Facultad de Letras Clásicas ponen como propósito más remoto la traducción de un texto latino, con la ayuda del diccionario y materiales de apoyo. Y no, "el alumno leerá con soltura, en prosa y en verso, la lengua latina"; tal vez esto se logrará con el ejercicio constante, y con un estudio riguroso después de varios años. Además este Manual está todavía en un nivel muy teórico. ¿Qué gramática está en el nivel práctico para aprender una lengua que no sea la nuestra? Aún nuestra lengua, no la hemos aprendido a hablar gramaticalmente; si por gramática se entiende el arte de hablar y escribir correctamente un idioma, o no muy lejos, declinar nombres 
o bien conjugar verbos. Todavía recuerdo que antes se nos decía, y lo insiste también con coraje el doctor Pedro Tapia Zúñiga: "el que conjuga y declina la lengua latina, sabe perfectamente la lengua latina". Pero esto no es verdad, insiste Tapia.

En los cursos de latín muchas veces se ha visto que algunos maestros sólo enseñan a sus discípulos a declinar y a conjugar y en eso consiste el examen de traducir una oración latina, y poner una oración en español y luego pasarla al latín; en esto consiste estudiar latín. Sin embargo, recordemos que hemos estado aprendiendo español a base de repetir palabras y escribirlas una y otra vez; y ya hasta después de varios años viene la gramática. Respecto a esto que acabo de afirmar, preguntarán algunos: ¿y esto qué tiene que ver con el Manual de Gramática Latina de Abel Alemán? Aquí es donde voy a resaltar el aspecto positivo de su Manual.

Si toda gramática de suyo es teórica, la parte práctica, por lo menos, aprender a traducir latín depende fundamentalmente de la lógica que le sepa dar el maestro que está enseñando esta lengua. Pienso que este manual debe ir acompañado con un método práctico para aprender a traducir latín. Considero que por los contenidos excelentes que tiene en morfología y sintaxis, bien se puede adaptar al método "lingua latina secundum naturae rationem explicata", que de hecho se basa en los siguientes pasos: lectura de un texto (con la fonética que se quiera), memorización del léxico del texto, gramática del texto (morfología y sintaxis), traducción y finalmente un pensum del texto en forma de cuestionarios a fin de pensar la lengua del texto que se está estudiando.

Así pues, si un maestro que enseña latín utiliza el Manual del profesor Abel Alemán de una forma horizontal, por supuesto que se quedará en la parte gramatical, porque por lo menos se requiere de unas 50 horas para conocer las nociones de morfología y sintaxis, y cuando se quiera pasar a la traducción de textos, el curso ya habrá llegado a su fin. Yen este sentido se caerá en el error que señalan muchos filólogos, de aprender solamente a declinar y a conjugar palabras sueltas de la lengua latina, y no traducir jamás un texto latino, para no decir un libro. Por el contrario, si este Manual de 
Gramática Latina se utiliza de una forma heterodoxa, partiendo de un texto latino, hay que ir aprendiendo la gramática, esto es, morfología y sintaxis; pero solamente la que vaya pidiendo el texto. Y pienso que en este sentido, el maestro y el alumno, en la obra de Abel Alemán, encontrarán la respuesta que explique el texto que están traduciendo. Por lo anterior, recomiendo este manual para otros maestros y también para mis alumnos.
En suma, a mi juicio considero que este Manual de Gramática Latina está muy bien hecho; su lectura es accesible y el método se presta para alumnos que de una forma autodidacta quieran iniciarse en esta lengua, aunque no del todo, porque es fundamental e indispensable la dirección de un maestro que sepa latín. En este Manual hay orden, disciplina y sabiduría. Además creo que se presentan las notas esenciales para aprender la lengua latina. 
